Article

\title{
Effects of Reinforcement Geometry on Strength and Stiffness in Adhesively Bonded Steel-Timber Flexural Beams
}

\author{
Parvez Alam $^{1, *}$, Martin Ansell ${ }^{2}$ and Dave Smedley ${ }^{3}$ \\ 1 Centre for Functional Materials, Abo Akademi University, Porthaninkatu 3, \\ Turku 20500-FIN, Finland \\ 2 Department of Mechanical Engineering, University of Bath, Bath BA27AY, UK; \\ E-Mail: M.P.Ansell@bath.ac.uk \\ 3 Rotafix Ltd., Abercraf, Swansea SA9 1UR, UK; E-Mail: Daverotafix@aol.com \\ * Author to whom correspondence should be addressed; E-Mail: parvez.alam@abo.fi; \\ Tel.: +358-2-2154858.
}

Received: 2 June 2012 / Accepted: 26 June 2012 / Published: 10 July 2012

\begin{abstract}
A finite element model is developed to analyse, as a function of volume fraction, the effects of reinforcement geometry and arrangement within a timber beam. The model is directly validated against experimental equivalents and found to never be mismatched by more than $8 \%$ in respect to yield strength predictions. Yield strength increases linearly as a function of increasing reinforcement volume fraction, while the flexural modulus follows more closely a power law regression fit. Reinforcement geometry and location of reinforcement are found to impact both the flexural properties of timber-steel composite beams and the changes due to an increase in volume fraction.
\end{abstract}

Keywords: simulation; timber; composites; buildings; materials; structural; mechanics

\section{Introduction}

Timber beams used in buildings that are subject to flexural deformation can benefit from the application of internal reinforcements such as flitch plates, and rectangular or solid cylinder rods inserted into routed groves. Such rods are used for repairing timber beams but also have significant potential for upgrading fast grown, low quality softwoods. Mild steel is most commonly used as good 
strength and stiffness properties can be obtained at much lower prices than fibre reinforced plastic (FRP) equivalents based on glass and carbon fibre.

Reinforcements are often applied to enhance the load bearing capabilities of structural timber. Flitch beams are a classic example of a steel reinforced timber beam which has been researched in detail during the early half of the 1970 [1,2]. In [1], two steel plate reinforcements were laminated between three timber members and mechanically connected by nails. The complete set-ups tested yielded on average, a $48 \%$ increase in the flexural stiffness and a $45 \%$ increase in flexural strength relative to un-reinforced timber beams. This traditional flitching method is nevertheless time consuming and cumbersome. Of the aforementioned papers [2] considered both mechanical and adhesive connection methods. Adhesive methods for joining reinforcements to timber are less cumbersome than drilling and fastening, but may require more time to complete since there is a period of curing during which essential cross linking takes place. In [2], adhesives were shown to outperform mechanical connectors for improving the flexural properties of the beams. Flitch beams are still in use [3]. Since the reinforcement runs through the entire depth of the beam and past the axis of neutrality, there is a degree of material wastage which could be circumvented by routing and inserting methods such as were researched by [4,5]. In [4], reinforcing rods were glued into a routed section vertically through the centre of timber beams which were subjected to flexural loads. These were compared against a secondary set of tests applying the same reinforcing procedure but replacing all centrally located rods with wood. The outermost reinforcements were kept. Since the failure loads in each of these beams was about the same, it was concluded that reinforcement located close to the neutral axis was in fact of little reinforcing benefit. In [5], miniature flitch plate reinforcements were positioned on the compressive faces of flexural timber beams. This prevents compressive buckling of the outermost compressive fibres of the wood and consequently the tensile load bearing capacity of the beam is fully exploited. Beams reinforced like this nevertheless, tend to fracture catastrophically. Ductile failure may be preferable and to take fuller advantage of compressive face ductility, reinforcements can be applied to solely the tensile faces of beams. Varying the positions of reinforcement moreover influences the modes and rates of failure [6,7], as well as the overall flexural strength.

Timber structures are normally designed so as to remain well within their elastic capabilities. Occasionally however, timber structures are under-designed and the onset of plastic yielding may endanger the lifetime of the structure, which is in turn a considerable safety hazard. A theoretical determination of the proportional limit is therefore paramount and is possible using an elastic-plastic analysis method. The objectives herein are to develop a non-linear finite element model to simulate the yield strength of four different reinforcement configurations, and to use the model to determine which reinforcement configuration is most effective in resisting load as a function of volume fraction. The reinforcing geometries and composites modelled are commonly used for repairing damaged structures [8]. For the benefit of small to medium enterprises that use these reinforcements; there still exists the need to categorically define the geometry that is actually most beneficial, and indeed the extent of its benefit over other commonly used reinforcing geometries. The modelling herein intends to address this need. 


\section{Experimental Procedure and Modelling Approach}

The models were developed in ANSYS 5.7. The validity of the model predictions were tested against experimental samples tested to destruction. This section begins by briefly describing the experimental series against which model predictions were compared.

\subsection{Experimental}

Figure 1 shows the cross sections of four different reinforcement configurations (Series I-IV). Series I composite beams were full depth flitch beams where the reinforcing steel was vertically laminated between two sections of Kerto S laminated veneer lumber (LVL) to a depth of $50 \mathrm{~mm}$ either side of the axis of neutrality. Testing carried out at the University of Bath on LVL specimens have shown the mean bending modulus is $12.4 \mathrm{GPa}, 50 \mathrm{MPa}$ value for strength, $0.62 \mathrm{GPa}$ value for the shear modulus and a Poisson's ratio of 0.29 . The LVL was cut to $110 \mathrm{~mm}$ to avoid geometric instability. Each beam was $1900 \mathrm{~mm}$ long. Series II beams were manufactured by bonding together two LVL sections (1900 mm long, $51 \mathrm{~mm}$ wide and $110 \mathrm{~mm}$ deep). A $40 \mathrm{~mm}$ deep and $12.7 \mathrm{~mm}$ wide groove was then routed along the centre of the beam axis on both the tensile and compressive faces of the beam. $40 \mathrm{~mm}$ deep reinforcements were then slotted and glued into the grooves on either face. Series III beams were, like series II beams, initially bonded together as vertically laminated LVL sections after which grooves were routed into the tensile and compressive faces of the beams but this time at a depth of $20 \mathrm{~mm}$ and a width of $12.7 \mathrm{~mm}$, with two grooves routed into each face in the centre and along the axis of each LVL segment. $20 \mathrm{~mm}$ deep reinforcing plates were then slotted and glued into the grooves located on either face. Series IV beams comprised two LVL sections vertically laminated together after which grooves were routed into the tensile and compressive faces using a round ended router. This would create a semi circle at the bottom of each groove. Two grooves were routed into both the tensile and compressive faces of the LVL beams. Each groove was situated at the centre of each LVL section. Reinforcements were this time inserted and glued into the grooves as circular rods. Three beams were made for each of the types of reinforcement totalling twelve beams. The dimensions of the reinforcements used were different as a result of commercial availability. For every beam, Rotafix CB10T slow set (CB10TSS) epoxy adhesive was used for joining the composite members. The mild steel, used during the experimental phase conforms to standards specified in BS 4360 (1986) [9].

Figure 1. Composite beam reinforcement configurations for series I, II, III and IV.

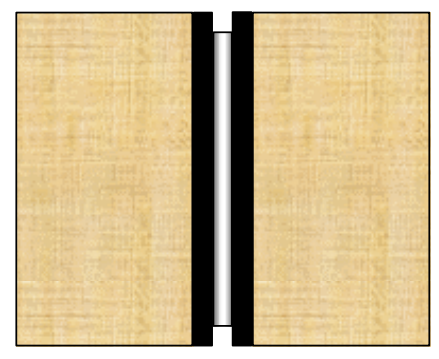

SERIES I

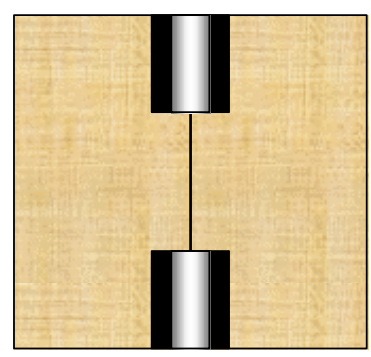

SERIES II

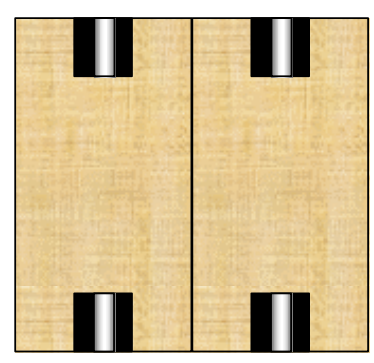

SERIES III

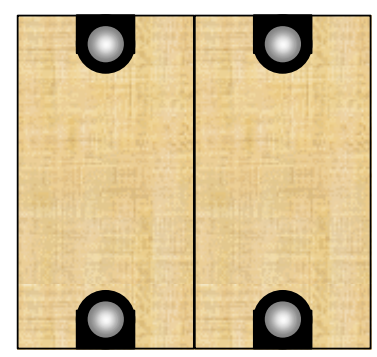

SERIES IV 
Composite beams were subjected to loading under conditions of four-point bending at a crosshead rate of $2 \mathrm{mmmin}^{-1}$. The beams were tested under service class 2 conditions [10] and the LVL retained a moisture content of approximately 12\%. An LVDT displacement transducer attached to the moving crosshead was used to monitor the centre point deflection. Figure 2 shows a schematic of the loading scheme.

Figure 2. Schematic of four-point bending test set up.

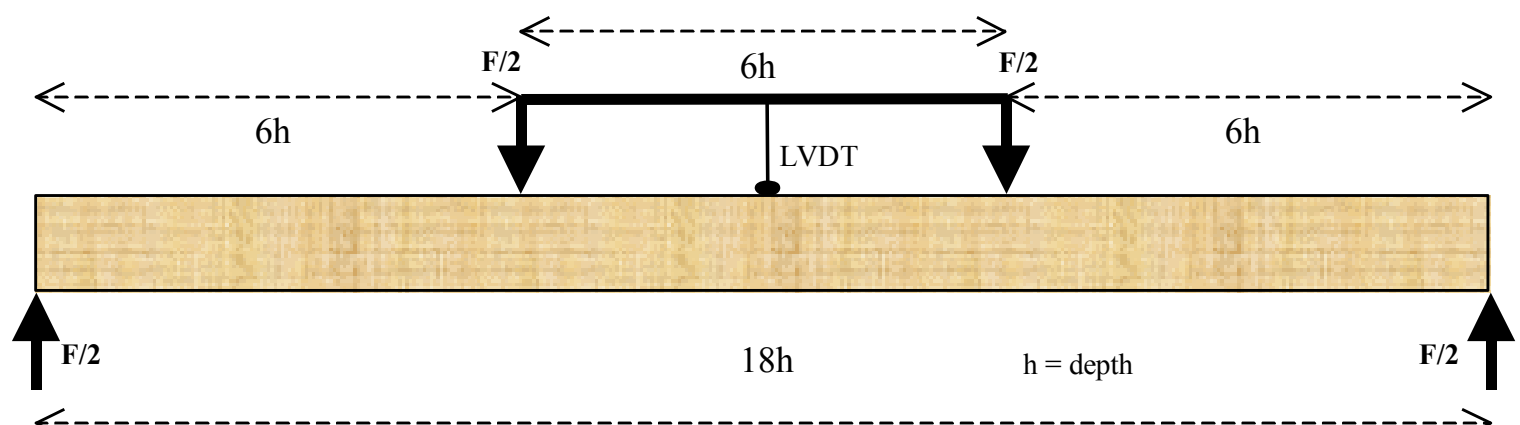

Reinforcing timber is a means by which low grade timbers can be upgraded, or, by which timber structures can be repaired [11]. In this test program, LVL was used because it has low variability in properties compared to low grade timbers. The number of reinforced beams tested in each series was low and focus was primarily on the effect of reinforcement geometry. Therefore, LVL was deemed an appropriate material to use to minimise variations in the composite properties that arise through the wood, as opposed to through the reinforcement and its geometry.

\subsection{Model Development}

Series I-IV beams were constructed according to the cross sectional dimensions shown in Figure 3, each component for each composite beam also having a length of $900 \mathrm{~mm}$. The cross sections modelled represent only one half of the actual beam cross sections due to symmetry. The modelled beam lengths were also symmetrical about their centre points and hence, only half the beam length needed to be modelled.

Node sharing contact between the beam components was specified for each beam. This assumed a theoretically perfect interface, which is infinitely thin and inseparable, even beyond the maximum bond stress capabilities of the adhesive-steel or adhesive-LVL interface. This approximation is acceptable provided there is no de-bonding between any of the adhesive interfaces throughout the duration of monitored loading (i.e., to slightly beyond the composite yield strength).

Series I-IV beam components were discretised using 1st order three-dimensional solid elements. Each element comprises eight nodes and three degrees of freedom exist at each node in the directions perpendicular and parallel to the LVL grain axis, which coincide with the orthogonal Cartesian axes $\mathrm{x}$, $\mathrm{y}$ and $\mathrm{z}$. The element edge lengths were defined according to the geometric requirements of each component within each model. The final mesh patterns for the cross sections of series I-IV composites are shown in Figure 4. 
Figure 3. Cross sectional dimensions and layout used in finite element models for beams from series I-IV (labelled). In each series, the laminated veneer lumber (LVL) is textured brown, the adhesive is black and the steel reinforcements are shaded grey.
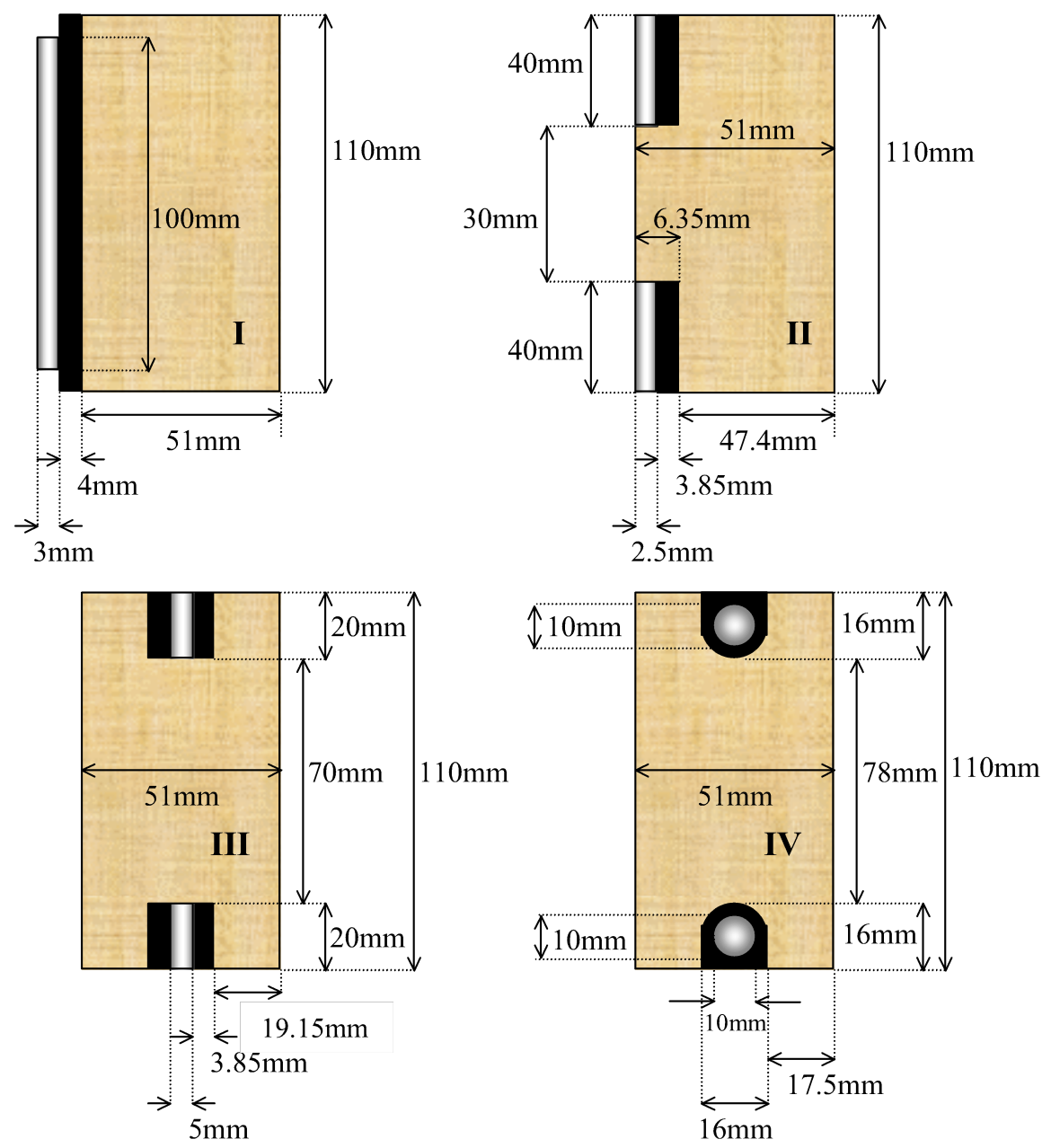

Figure 4. Mesh patterns of cross sections for composite beams in series I-IV.

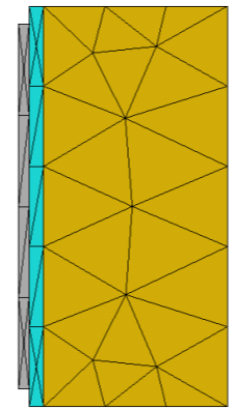

Series 1

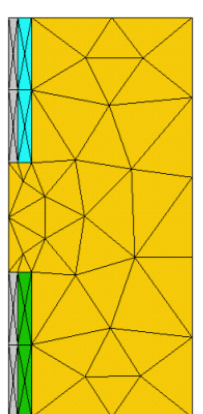

Series II

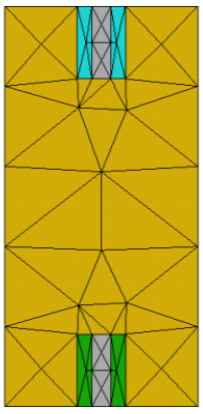

Series III

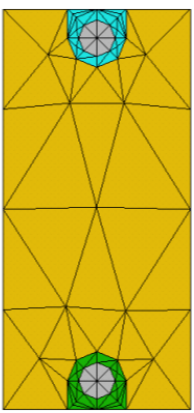

Series IV

Stress-strain characteristics of steel are adequately represented using bi-linear plots where the onset of yield is defined and work hardening is taken to $15 \%$ strain. The steel is assumed to be an isotropic solid with a density of $7900 \mathrm{kgm}^{-3}$, a shear modulus of $83 \mathrm{GPa}$, an elastic modulus of $210 \mathrm{GPa}$ and a Poisson's ratio of 0.27 . Work hardening in the steel begins at the critical von-Mises stress, $\sigma_{v}$. This stress is calculated according to the principle, $\sigma_{v}=\sqrt{\left(\sigma_{1}-\sigma_{2}\right)^{2}+\left(\sigma_{2}-\sigma_{3}\right)^{2}+\left(\sigma_{3}-\sigma_{1}\right)^{2}}$ and nonlinearity 
begins at $300 \mathrm{MPa}$. The subscripts ${ }_{1,2}$, and ${ }_{3}$ refer to the individual principal axes of the steel, which are coincident with the orthogonal Cartesian axes.

The tensile and compressive characteristics of Rotafix CB10TSS adhesive were approximated to elastic-perfectly-plastic systems. Tests were performed on clear samples of CB10TSS. Tensile tests were performed on three samples of CB10TSS, which had a thickness of $4 \mathrm{~mm}$ and a width of $10 \mathrm{~mm}$. An extensometer was used to measure the strain as a function of loading. The values for the compressive properties of CB10TSS adhesive were provided by the manufacturer, Rotafix Ltd. The elastic moduli of CB10TSS adhesive are the same in tension and compression, however, the compressive strength of this adhesive is superior to its strength in tension. Figure 5 shows the elastic-perfectly-plastic tensile and compressive characteristics input into the model.

Figure 5. Elastic rigid-plastic stress-strain relationships for the adhesive in tension and compression.

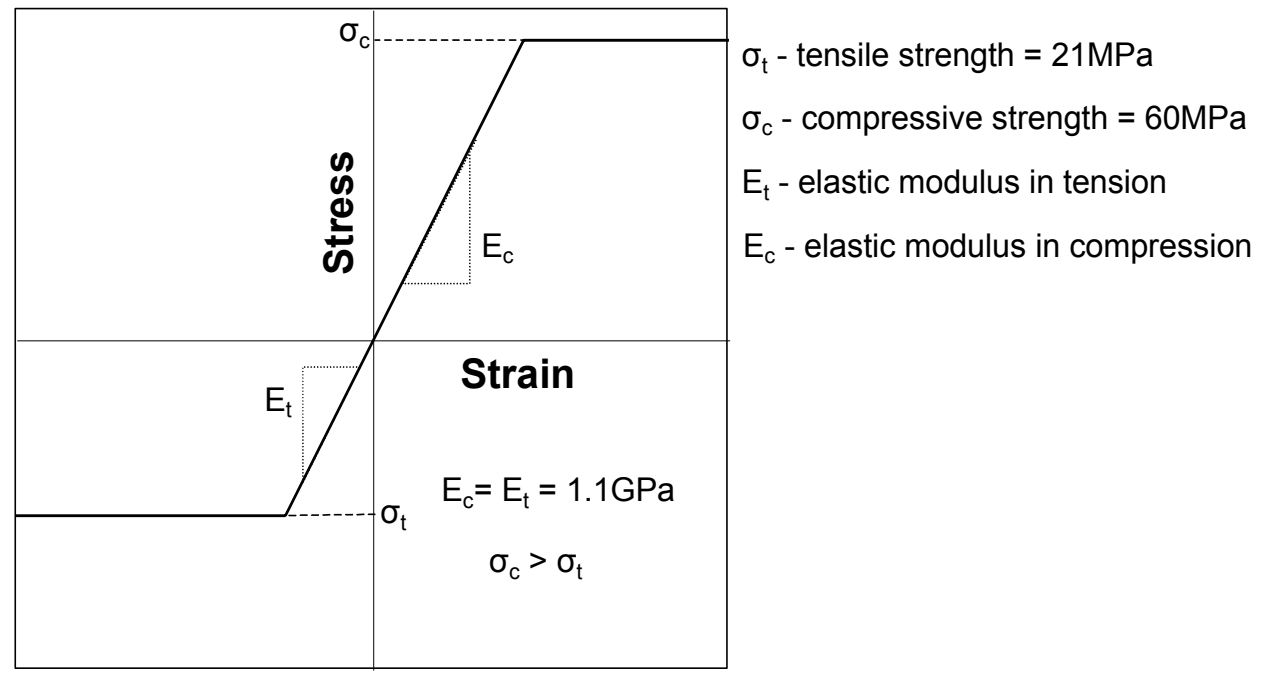

The LVL was modelled as an orthotropic elastic-anisotropic plastic material with a density of $520 \mathrm{kgm}^{-3}$. The elastic constants are provided in Table 1 and the Cartesian $\mathrm{x}$-axis is considered parallel to the grain of the LVL. Although orthotropy is assumed, the elastic constants for the two axes normal to the direction of the grain were normalised such that; $\mathrm{Ex} \neq \mathrm{Ey}=\mathrm{Ez}$ and $v \mathrm{xy}=v \mathrm{xz} \neq v \mathrm{yz}$. The values are in accordance with tests conducted at the University of Bath. The E value used here is slightly higher than the value of $12.4 \mathrm{GPa}$. This was necessary to circumvent convergence problems associated with the consistency criteria for elastic constants in the orthotropic model simulation.

Table 1. Elastic properties of Kerto S laminated veneer lumber.

\begin{tabular}{|c|c|c|c|c|c|c|}
\hline \multirow{2}{*}{ Property } & \multicolumn{6}{|c|}{ Direction or plane } \\
\hline & $\mathbf{x}$ & $\mathbf{y}$ & $\mathbf{z}$ & $\mathbf{x y}$ & $\mathbf{y z}$ & $\mathbf{x z}$ \\
\hline E/GPa & 12.75 & 0.255 & 0.255 & - & - & - \\
\hline G/GPa & - & - & - & 0.62 & 0.62 & 0.62 \\
\hline$v$ & - & - & - & 0.03 & 0.29 & 0.03 \\
\hline
\end{tabular}

Normal yield stresses in compression, $\sigma_{\mathrm{cy}}$, were defined in the orthotropic principal axes of the LVL, which were taken to coincide with the local orthogonal Cartesian axes, the $x$ axis of which is normalised with the grain axis of the LVL. Yielding in tension was not specified as it was assumed that 
the behaviour of the LVL in tension was linear elastic throughout the duration of loading. Peak shear stresses, $\tau_{\mathrm{p}}$, were also identified and defined in the $\mathrm{xy}, \mathrm{yz}$ and $\mathrm{xz}$ planes. Following yielding in compression or shear, tangent moduli and tangent shear moduli describe the plastic stress-strain relationships in each direction and plane.

It is incorrect to specify solely the non-linear compressive characteristics of LVL for beams subjected to flexure. Although such an approximation may be valid for compression dominated failure, there will certainly be the development of high tensile stresses on the underside of a bending beam below the neutral axis. Plastic incompressibility restricts the use of both tensile and compressive characteristics in the same model. The problem is overcome by linearly interpolating between the data predictions of two models, one possessing the tensile characteristics of LVL and the other with the compressive characteristics. Given that there is symmetry about the axis of neutrality prior to loading, it is plausible to assume that exactly half the beam experiences tension, whilst the other half is subjected to compression. This approximation essentially violates true beam behaviour whereby the neutral axis moves closer to the tensile edge of the beam at the onset of compressive yielding. It is however an easily applicable approximation that minimises the errors associated with leaving out the characteristics of tensile failure altogether.

The normal compressive and shear yield stresses as well as the gradients describing the 1st order (linearly) proportional plastic stress against plastic strain were determined through experimental compression and shear block testing of LVL specimens with dimensions of $(50 \mathrm{~mm})^{3}$. These tests were conducted at a displacement rate of $2 \mathrm{mmmin}^{-1}$. The tangent moduli for the compression block tests were measured at a $0.2 \%$ proof stress. A strain of $0.2 \%$ was chosen to ensure that the slope of the tangent corresponded with the slope of the linear plastic stress-strain gradient. The bi-linear stress-strain plots for the shear planes $\mathrm{xy}, \mathrm{yz}$ and $\mathrm{xz}$ followed the appropriate shear modulus in each plane until reaching the peak shear stress of the material, after which the plastic slope supposed a zero tangent modulus. Figure 6 illustrates the tensile-compressive characteristics defined for the LVL, while the shear characteristics input into the model are shown in Figure 7. Though wood failing in shear is typically brittle, perfect plasticity had to be specified to avoid convergence problems associated with sudden drops in the material parameters.

Figure 6. Stress-strain approximations and related values for LVL in each principal axis.

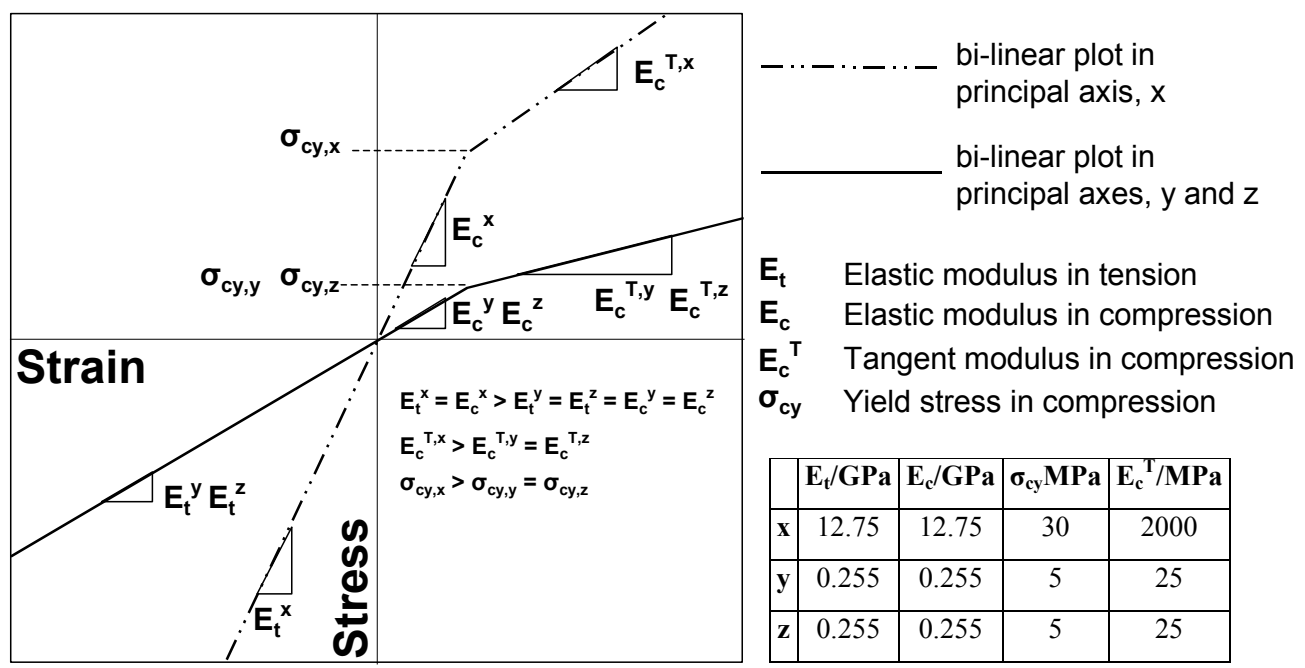


Figure 7. Bi-linear stress-strain approximations and related values for LVL in $x y, y z$ and xz shear planes.

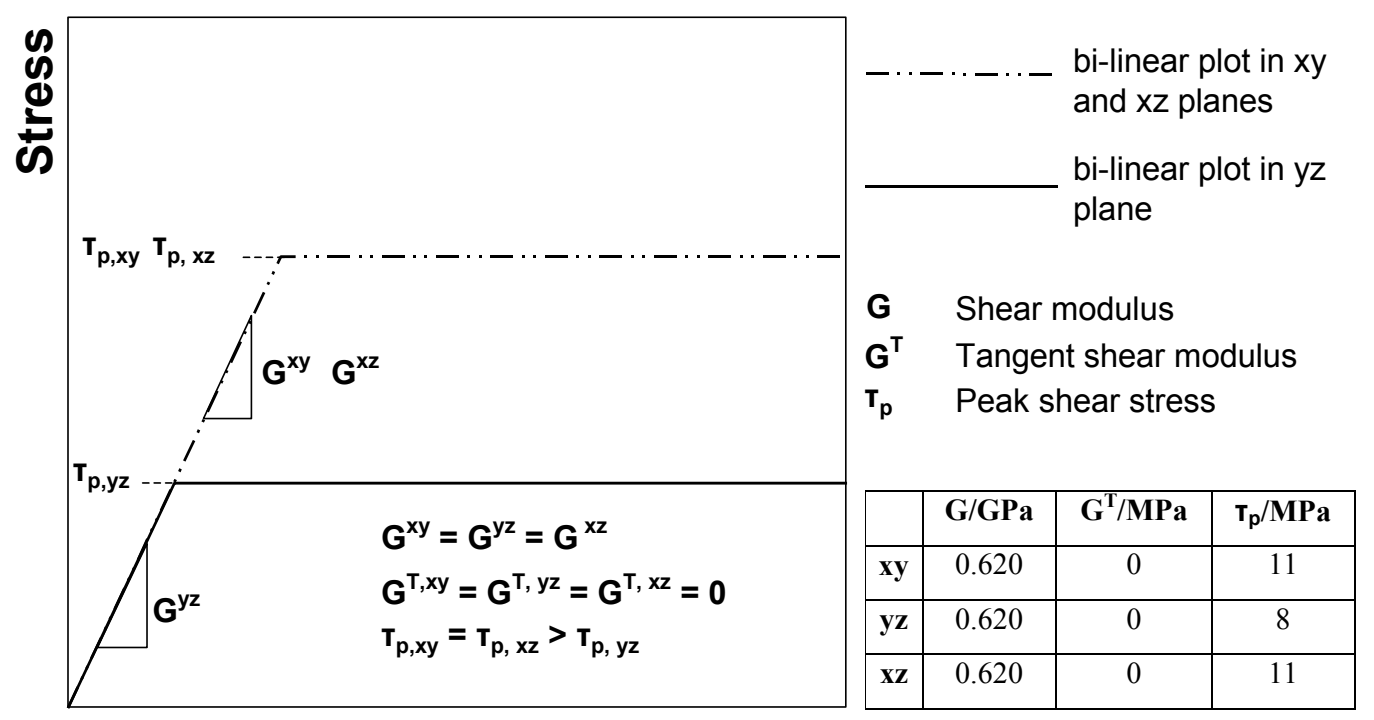

Strain

The model was symmetrised about $1 / 21$ and $1 / 2 b$, where 1 is the span and $b$ is the width of an entire composite beam such as was tested in series I-IV. Displacement controlled loading was applied via nodes attached to a line across the upper edge of the LVL segments for all beams (series I-IV). The line was located at a distance of $300 \mathrm{~mm}$ from the centre point of the beam. Force would be transferred therefore, through the LVL to the reinforcement via the adhesive. Nodal translations at the lower edge of the beam end were restricted in every degree of freedom along the Cartesian axes at a position on the lower edge of the beam at a distance of $900 \mathrm{~mm}$ along the span from the centre point of the beam. Rotational freedom was left unrestricted.

\subsection{Parameter Study}

Computer simulations were carried out for five different reinforcement volume fractions to predict the flexural yield strength and stiffness properties of series I-IV composite beams. The width of series I-III steel plates and the diameter of series IV steel rods were adjusted to yield reinforcement volume fractions of $1 \%, 2 \%, 2.8 \%, 4 \%$ and $5 \%$. The fraction of $2.8 \%$ was used as opposed to $3 \%$ since the full depth flitch beam had this fraction in the original simulations/experiments and it was deemed more efficient to bring reinforcements from the other series' to this fraction.

\section{Results}

\subsection{Comparison between Model Predictions and Experimental Test Results}

Finite element predictions for series I-IV composite beams are compared with the experimental load-displacement characteristics (grey lines) for series I-IV and are shown in Figures 8-11. The limit of elastic proportionality is determined by approximating the finite element predictions to an initial 1st order relationship representing elasticity and a subsequent 1st order relationship representing plasticity. The intersection between the two linear estimations is taken to be the proportional limit, or, the yield 
load. Ratios of the predicted force at yield to the experimentally determined forces at yield are calculated and tabulated to two decimal places in order of magnitude. A value above or below unity signifies an over or under prediction respectively. The closer the ratio is to unity, the closer the FE predictions are to the experimental observations. Statistically, the values within each series are very close as is indicated by the coefficients of variation $(\mathrm{CoV})$; series $\mathrm{I} \mathrm{CoV}=0.01$, series II $\mathrm{CoV}=0.03$, series III $\mathrm{CoV}=0.04$ and series IV $\mathrm{CoV}=0.01$.

Figure 8. Load-displacement curves for series I tested steel-reinforced LVL samples (in grey) and estimated finite element predictions (black dots). A comparison is made between the predicted and experimental proportional limits.

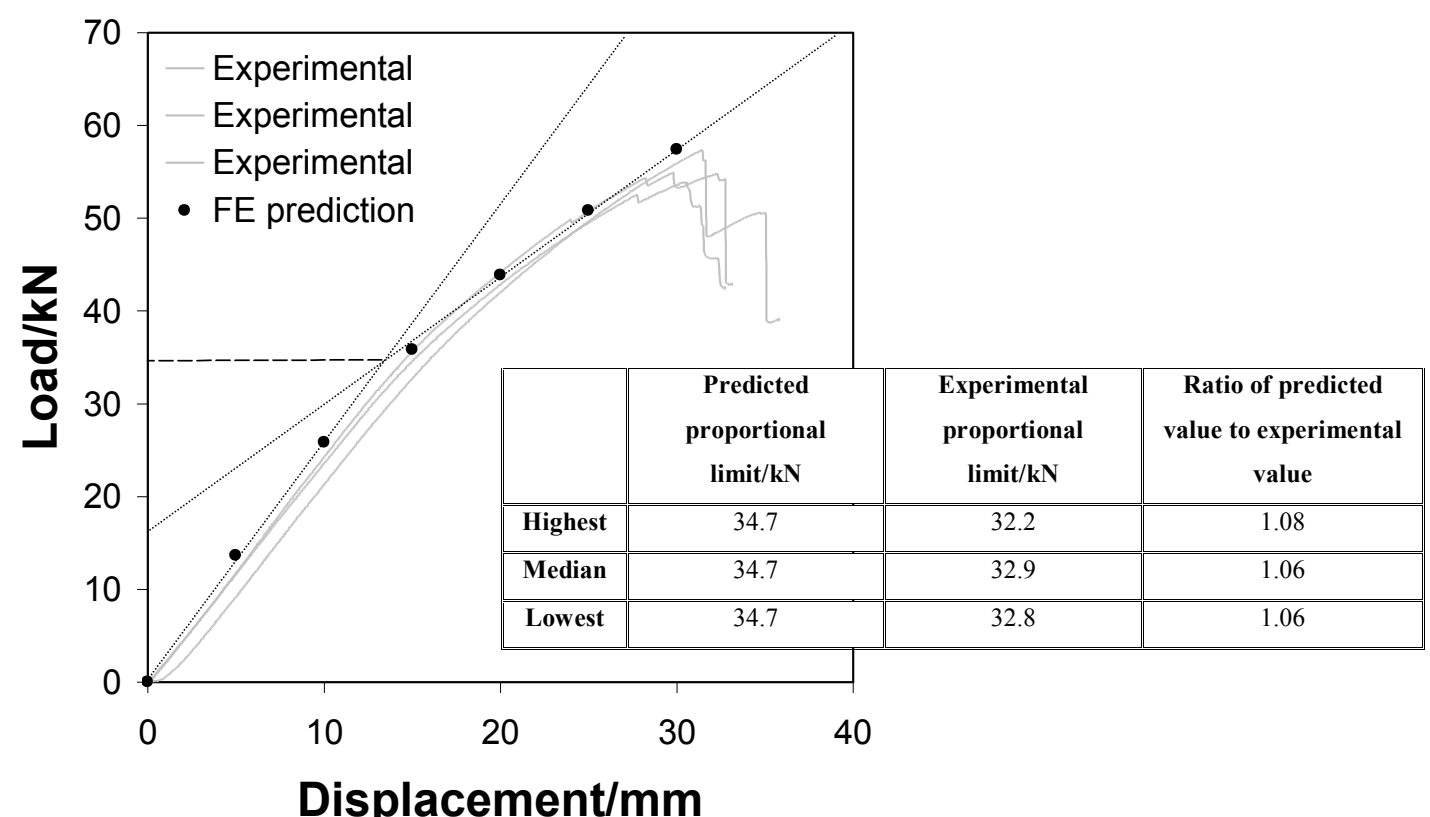

Figure 9. Load-displacement curves for series II tested steel-reinforced LVL samples (in grey) and estimated finite element predictions (black dots). A comparison is made between the predicted and experimental proportional limits.

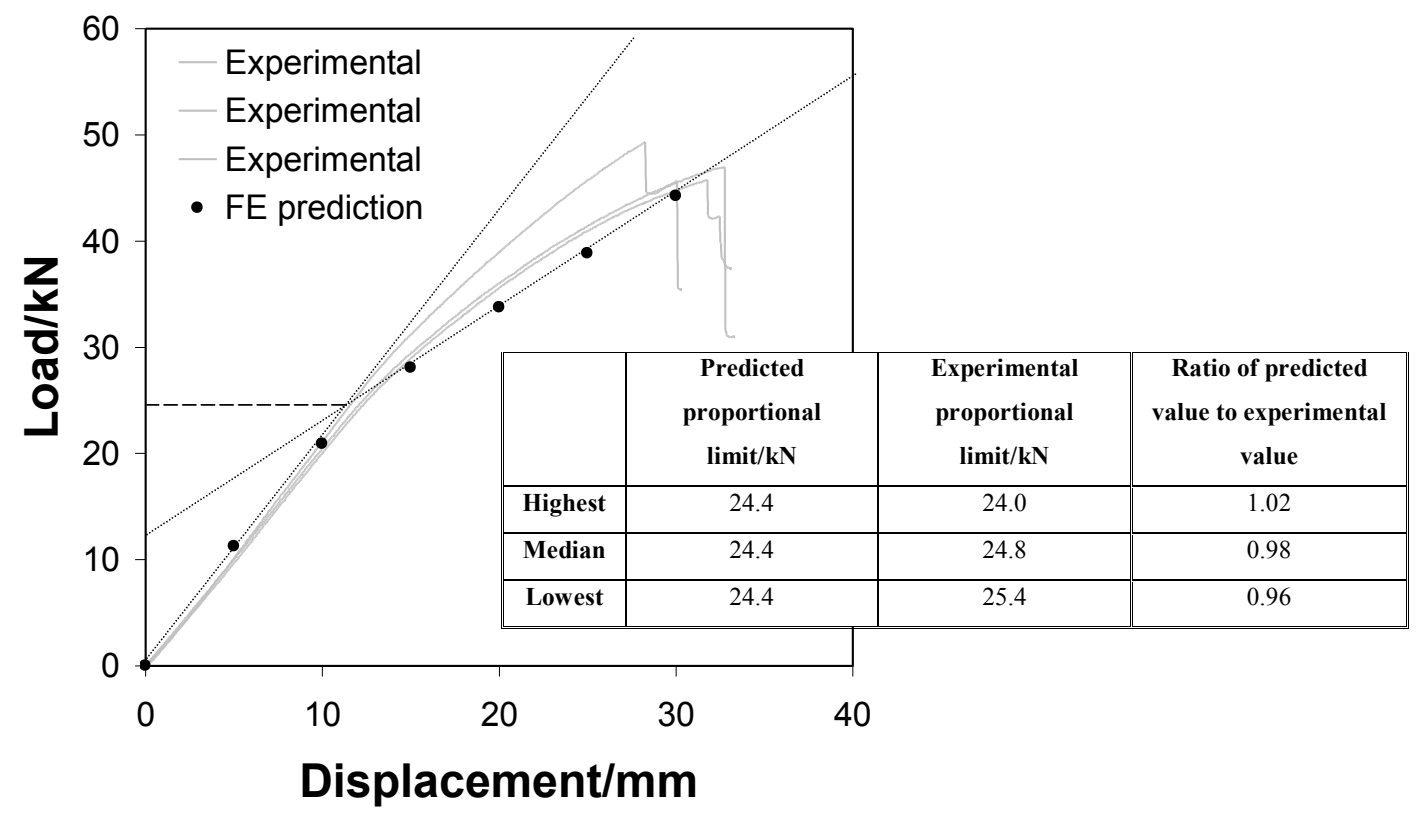


Figure 10. Load-displacement curves for series III tested steel-reinforced LVL samples (in grey) and estimated finite element predictions (black dots). A comparison is made between the predicted and experimental proportional limits.

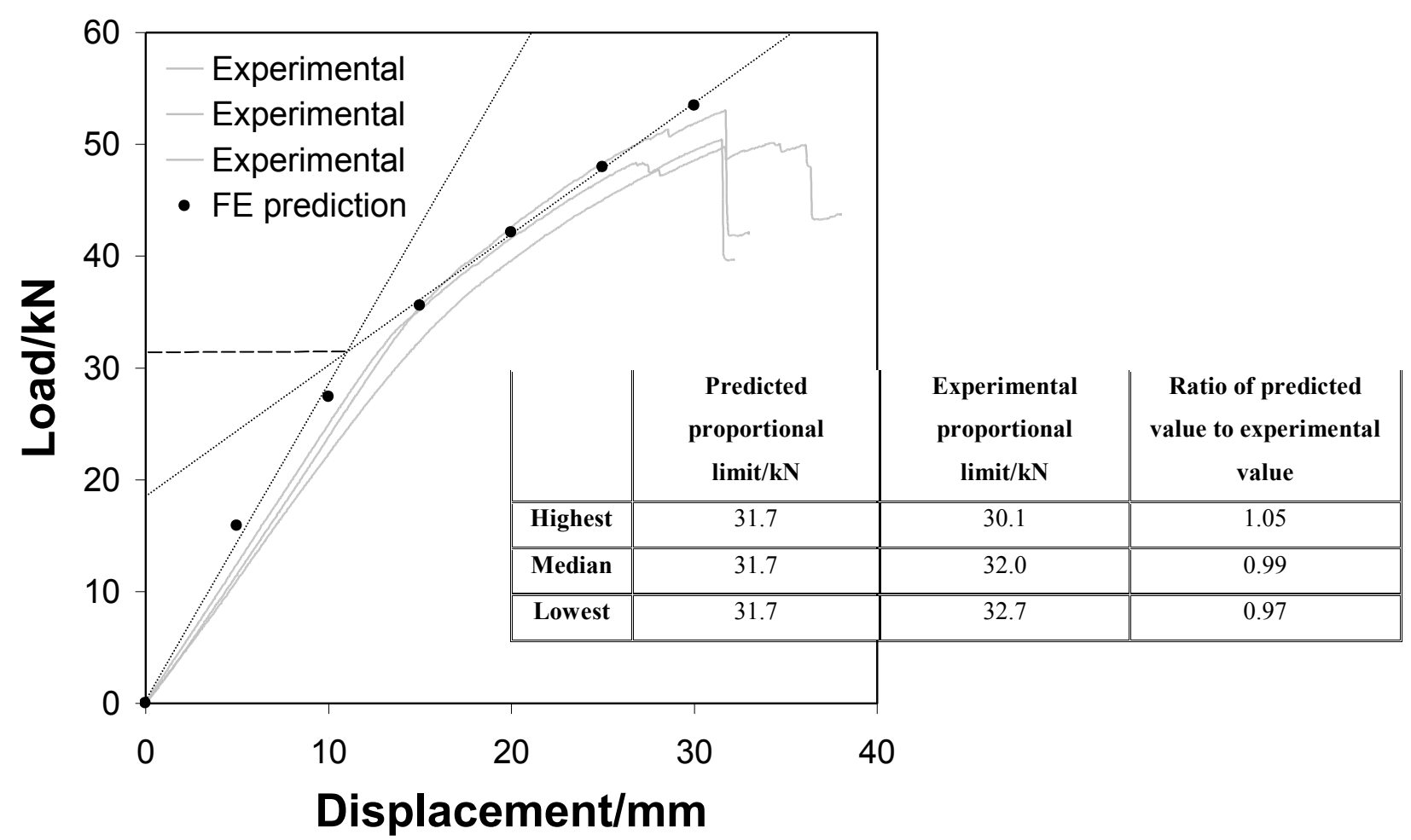

Figure 11. Load-displacement curves for series IV tested steel-reinforced LVL samples (in grey) and estimated finite element predictions (black dots). A comparison is made between the predicted and experimental proportional limits.

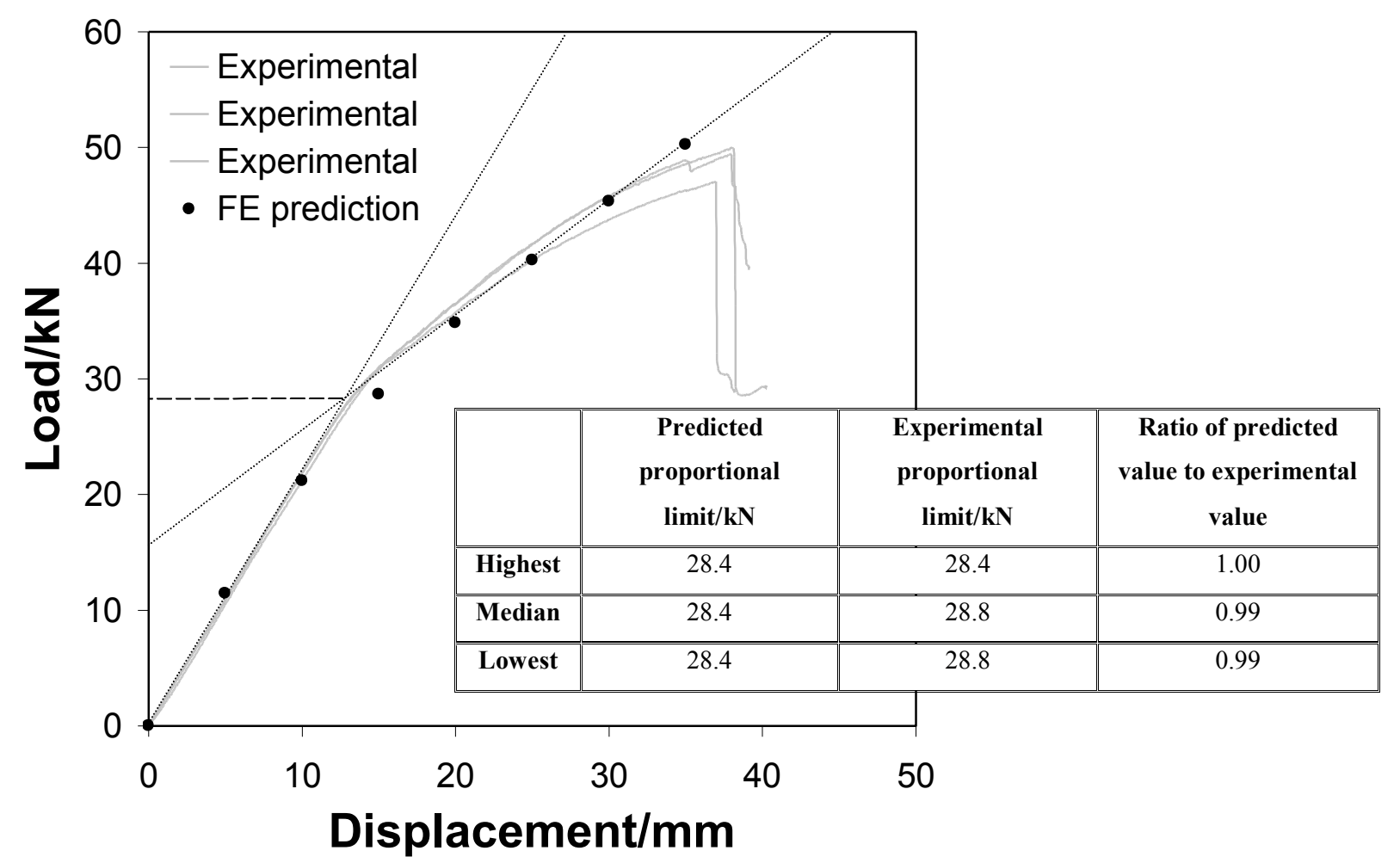


On examining the tables in Figures $8-11$, the model predictions can be seen to be at worst, $\pm 8 \%$ different to the experimental values for the proportional limit. The slope of the initial linear portion, prior to yielding, shows little variation between experimental and predicted values. The largest variance is in the series III predictions where the predicted initial (elastic) slope is distinctly higher than the experimental values. This shifts the intersection between the two lines and decreases the yield strength prediction.

A sound estimate of the linear tangent and the force at yield is vital when designing timber structures. The aim of design is to remain within safe limits and to avoid loading above composite yield. Theoretical studies of reinforced timber composites have employed moment relationships based upon the failure modes of composite beams to predict the ultimate failure loads [12-14]. Others have presumed that a maximum shear stress criterion is enough to predict the ultimate load of a reinforced timber beam [15]. The aforementioned studies are all inclined towards predicting the ultimate failure using uni-directional analytical procedure. It could be argued that the prediction of the proportional limit is at least as useful, if not more useful for designers because the design objective is to never exceed the proportional limit. The non-linear finite element predictions show considerable accuracy and could therefore be useful for designing safe structures.

Having ascertained that the model predictions are close to the experimental equivalents, the next stage was to compare the effects of individual reinforcing geometries as a function of volume fraction, on the yield strength and stiffness properties of the composite beams.

\subsection{Flexural Properties}

Figures 12,13 show the predicted composite flexural moduli and yield strengths for series I-IV beams expressed as a function of reinforcement (steel) volume fraction. These figures clearly demonstrate the importance of each reinforcement arrangement and geometry. Of the differing configurations, the best flexural modulus and yield strength values are obtained by inserting smaller vertical laminates closer to the outermost fibres of the LVL (as in series III composites). This geometry is predicted to be better also than reinforcing rods that are similarly located within the LVL (as in series IV). The geometry of vertical laminates allows a greater percentage of the reinforcement to be located near the outermost fibres whereas reinforcing rods are thickest at a distance of at least the rod radius from its edge. Rods are therefore less effective than plates for reinforcing the beam surface. The reinforcement volume fractions remain constant for the sake of comparison.

The trends between reinforcement series I-IV are the same for the flexural modulus and the yield stress. Series II yield stress nevertheless exhibit slight deviation from those general trends observed for series I, III and IV. Here it can be noted from the coefficients of determination that there is greater scatter in the series II simulations than in any of the others, which gives rise to the intersection between series II and III regression fits. This anomaly is most likely an effect of using an insufficient mesh density in series II models. The predicted flexural modulus values fit well to a non-linear trend and confirm the experimental findings of [16] as well as the theoretical deductions of [11]. The yield stresses suppose a 1st order fit as a function of the reinforcement volume fraction and are in this respect, dissimilar to the trends for the elastic moduli seen in Figure 12. There are neither experimental nor theoretical data available in the literature for a yield strength expressed as a function of the 
reinforcement volume fraction (for reinforced timber beams). It can be hypothesised that the linearity of this material property as a function of the reinforcement volume fraction is attributable to the yield stress of steel. The yield stress of steel may well exhibit linearity as a function of its geometry and volume. Larger sections of steel can resist higher forces and hence constrain the onset of yield more effectively than smaller sections of steel. It can therefore be suggested that the composite yield strength is governed by the yielding characteristics of the reinforcement provided it is the first component to yield in the composite. This is therefore true for steel reinforced LVL beams as steel has a significantly lower yield strain than LVL. Therefore, non-linear composite behaviour can be considered as beginning simultaneously with non-linear reinforcement behaviour.

The yield strain of mild steel is approximately 0.0015 . Increased resistance to flexure as a function of load is possible by increasing the volume fraction of reinforcement or indeed, by employing different reinforcement geometries. It is nevertheless plausible to suggest that once the yield strain of the steel reinforcement is surpassed, the magnitude of loading will no longer increase as dramatically as it does within the Hookean region of elasticity. This is evidenced when the magnitude of difference within each series as a function of volume reinforcement fraction is compared for the elastic modulus against the yield strength. The different reinforcement geometries used in series I-IV composite beams will resist higher loads to achieve a strain of 0.0015 as a result of the effectiveness of their location within the LVL, as a consequence of their local geometries and as a function of increasing volume fraction.

Figure 12. Finite element model predictions for the flexural modulus plotted as a function of the reinforcement volume fraction for series I-IV steel-LVL composite beams.

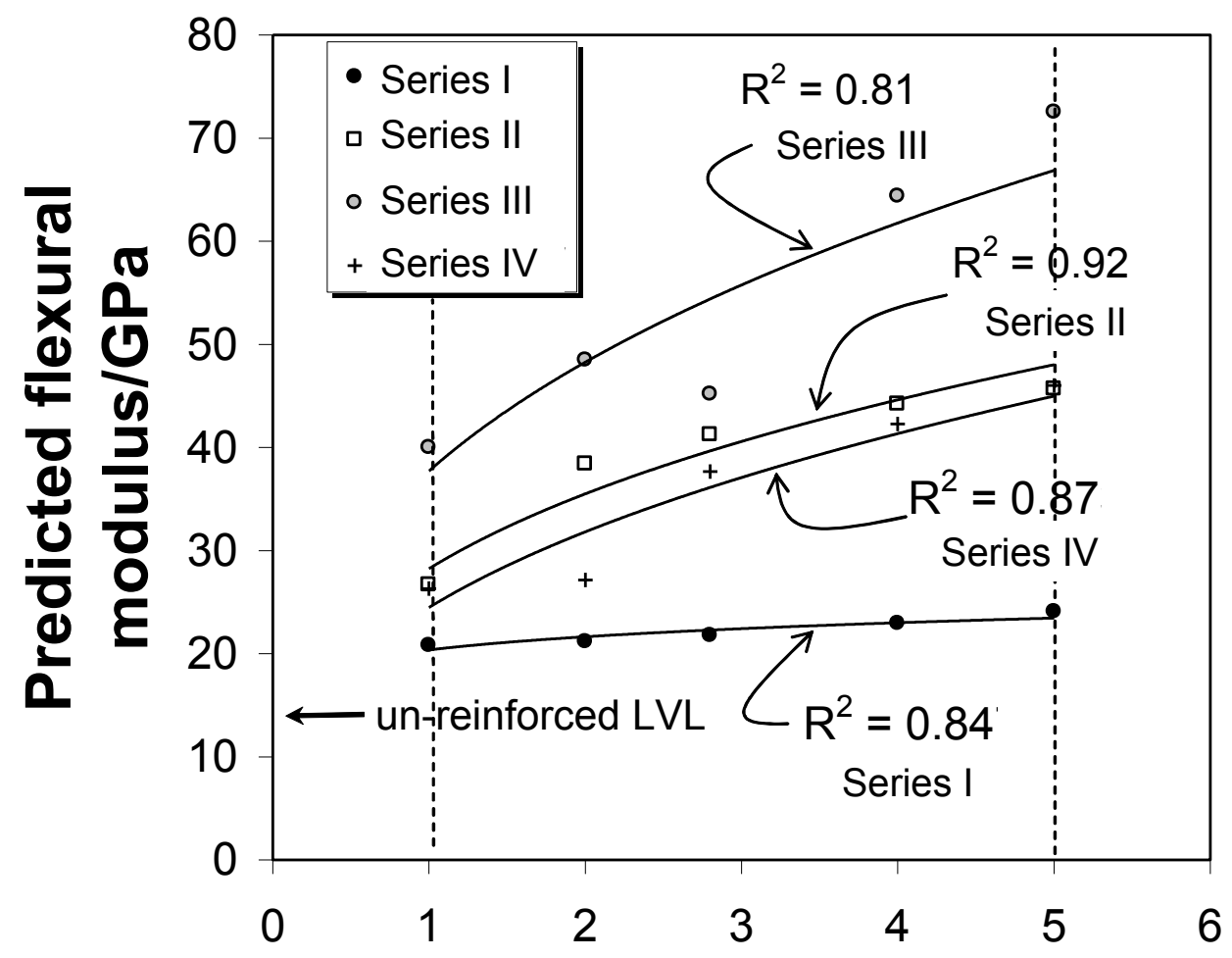

Reinforcement volume fraction/\% 
Figure 13. Finite element model predictions of the yield strength plotted as a function of the reinforcement volume fraction for series I-IV steel-LVL composite beams.

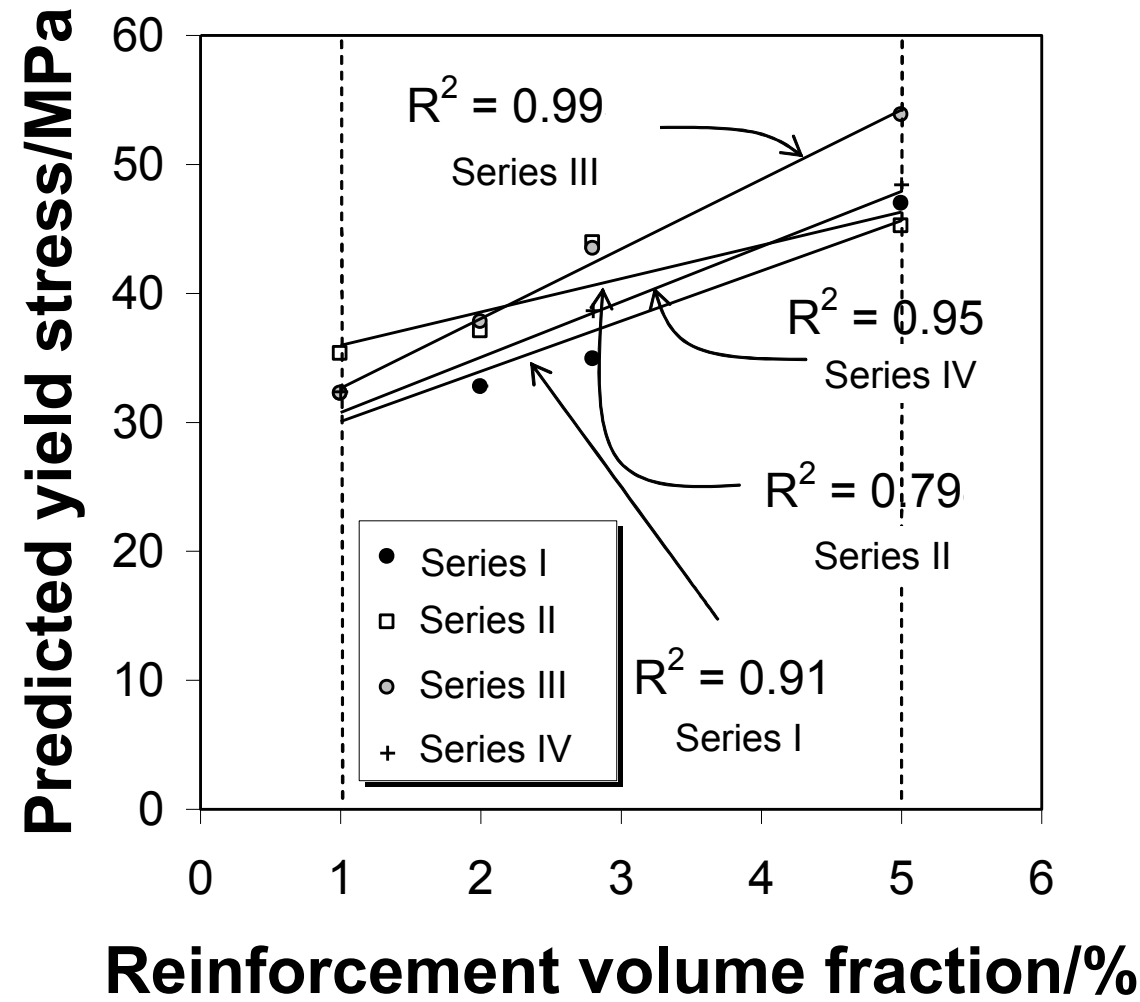

\section{Conclusions}

An assessment of the load bearing benefits of reinforcement geometry and location within flexural timber has been possible by developing a non-linear finite element model. The model has been used to predict the flexural modulus and yield strength of steel-LVL composites retaining equal volume fractions of reinforcement. These models have been verified by comparison to experimental equivalents and show a maximum error of $8 \%$ for yield strength predictions. Model predictions show that for volume fractions of steel reinforcement between $1 \%$ and $5 \%$, the flexural modulus of series I-IV beams can fit a power law trend relatively well, while the yield strength of series I-IV beams can be represented linearly. Model predictions suggest that the series III reinforcement configuration (small vertical plates located at the outermost fibres) give the greatest stiffness enhancement for LVL and produce the highest yield strengths out of the four reinforcement configurations (series I-IV).

In the design of flexion resisting members in buildings, the mechanical stability of a beam is often weighed against material cost and more recently, environmental impact. Moreover, in view of aesthetical impact, reinforcements may be positioned internally to a structural member, rather than externally. Rectangular section reinforcements located close to the outermost fibres of a beam in flexure have the greatest benefit in view of yield strength and stiffness improvement and moreover, give rise to reduced material wastage and economic loss. The yield strength is a most important design parameter as it indicates the onset of building failure and there is benefit therefore, not only in maximising this parameter, but also in predicting its value. The present study shows how this parameter can be accurately predicted and indeed, how reinforcement geometry is a significant design consideration for flexural beams. 


\section{References}

1. Stern, E.G.; Kumar, V.K. Flitch beams. For. Prod. J. 1973, 23, 40-47.

2. Coleman, G.E.; Hurst, H.T. Timber structures reinforced with light gage steel. For. Prod. J. 1974, 24, 45-53.

3. Ban, S.; Tsubota, H.; Motohashi, S.; Yoshida, A. Nagano Olympic Memorial Arena. In Proceedings of the Pacific Timber Engineering Conference, Rotorua, New Zealand, 14-18 March 1999; pp. 139-230.

4. Jones, R. Upgrading of timber members in historic buildings. J. Inst. Wood Sci. 1997, 14, 192-203.

5. Borgin, K.B.; Loedolff, G.F.; Saunders, G.R. Laminated wood beams reinforced with steel strips. ASCE J. Struct. Div. 1968, 94, 1681-1705.

6. Dziuba, T. The ultimate strength of wooden beams with tension reinforcement. Holzforsch. Holzverwert. 1985, 37, 115-119.

7. Brunner, M.; Schnueriger, M. Timber beams strengthened with prestressed fibres: Delamination. In Proceedings of the 8th World Conference on Timber Engineering (WCTE2004), Lahti, Finland, 14-17 June 2004; Volume 1, pp. 345-350.

8. Smedley, D.; Alam, P.; Ansell, M.P. George street, St. Albans, UK; A case study in the repair of historic timber structures using bonded-in pultruded plates. In Proceedings of ACIC07 Advanced Composites in Construction, Bath, UK, 2-4 April 2007.

9. $\quad$ BS 4360 Hot Rolled Weldable Structural Steel; British Standards Institution: London, UK, 1986.

10. Part 1.1: General rules and rules for buildings. In DD ENV1995-1-1. Eurocode 5: Design of Timber Structures; British Standards Institution: London, UK, 1994.

11. Alam, P.; Ansell, M.P.; Smedley, D. Mechanical repair of timber beams fractured in flexure using bonded-in reinforcments. Compos. Part B Eng. 2009, 40, 95-106.

12. Dagher, H.J.; Kimball, T.E.; Shaler, M.; Abdel-Magid, B. Effect of FRP reinforcement of low grade eastern hemlock glulams. In Proceedings of National Conference on Wood Transportation Structures, Madison, WI, USA, 23-25 October 1996.

13. Gilfillan, R.; Gilbert, S.; Patrick, G. The improved performance of home-grown timber glulam beams using fibre reinforcement. J. Inst. Wood Sci. 2001, 15, 307-317.

14. Fiorelli, J.; Dias, A.A. Analysis of the strength and stiffness of timber beams reinforced with carbon fibre and glass fibre. Mater. Res. 2003, 6, 1-10.

15. Dorey, A.B.; Cheng, J.J.R. Glass Fibre Reinforced Glued Laminated Wood Beams; CanadaAlberta Partnership Agreement in Forestry: Edmonton, AB, Canada, 1996.

16. Dorey, A.B.; Cheng, J.J.R. Development of a Composite Glued Laminated Timber; CanadaAlberta Partnership Agreement in Forestry: Edmonton, AB, Canada, 1996.

(C) 2012 by the authors; licensee MDPI, Basel, Switzerland. This article is an open access article distributed under the terms and conditions of the Creative Commons Attribution license (http://creativecommons.org/licenses/by/3.0/). 